\title{
UNA APROXIMACIÓN A LOS ESTUDIOS TECNOLÓGICOS DE LOS TORTEROS INDÍGENAS DE LAS SIERRAS DE CÓRDOBA (ARGENTINA)
}

\author{
Luis Tissera
}

Recibido: 8 de abril de 2018. Aceptado: 20 de octubre de 2018

\begin{abstract}
Resumen
En este aporte se efectúa el análisis preliminar de un conjunto de torteros cerámicos (contrapesos del huso para tareas del hilado), proveniente de diversos reservorios museológicos de la provincia de Córdoba. Se consideran características tecno-funcionales a partir de variables mensurables y se indaga en las posibilidades de producción que admiten estos artefactos. La mayoría de los mismos fueron producidos a partir de tiestos provenientes de distintos contenedores cerámicos, posiblemente descartados por roturas. Esta forma de producción, a través del reciclado, implicó una práctica ampliamente difundida a nivel regional; sin embargo, en hallazgos puntuales y acotados espacialmente, se puede observar otro tipo de tortero generalmente adornado con decoración incisa, cuya elaboración se caracteriza por la técnica de modelado y horneado de la cerámica. Entre los elementos de este tipo que integran la muestra, se observa un significativo predominio de aquellos artefactos procedentes del sur del Valle de Calamuchita, los que presentan una mayor especificidad tecnológica y funcional que delimita sus prestaciones. A partir del estudio comparativo entre este subconjunto y el resto de los torteros recuperados, se sugiere a modo hipótesis que entre1@s hilander@s de dicha área, podría haberse difundido una preferencia productiva en la elaboración de hilos de determinadas características.
\end{abstract}

Palabras claves: torteros, preferencia productiva, sierras de Córdoba, análisis tecnológico y funcional, Valle de Calamuchita

\begin{abstract}
In this work, a preliminary analysis of a set of ceramic spindle whorls (counter weights for spinning tasks), from various museological reservoirs of the province of Córdoba, is carried out. Techno-functional characteristics from measurable variables and it is investigated in the production possibilities that these artifacts admit, are considered. Most of them were produced coming from sherds from different ceramic containers, possibly discarded by breakages. This form of production, through recycling, involved widespread practice at the regional level, however, in specific finding and bounded spatiality limited we can see another type of spindle whorls, generally decorated with incised decoration, whose development is characterized by the modeling and baking technique of ceramics. Among the elements of this type that make up the sample, there is a significant predominance of those artifacts coming from the south of the Calamuchita Valley, which present a greater technological and functional specificity that delimits their performance. From the comparative study between this subset and the rest of the recovered spindle whorls, it is suggested in hypothesis that the spinners of this area show a productive preference in the elaboration of threads of certain characteristics.

Key words: spindle whorls, productive preference, Cordoba mountains, technological and functional analysis, Calamuchita Valley.
\end{abstract}

1 Reserva Cultural Natural Cerro Colorado (Dirección de Patrimonio Cultural - Agencia CórdobaCultura); Gobernador Olmos 2619, Villa Carlos Paz (5152), Provincia de Córdoba.

E-mail: luistissera@gmail.com 


\section{Introducción y antecedentes}

Los torteros o muyunas son artefactos que, eventualmente integran la cadena operativa de la producción textil y que se utilizan como contrapesos del huso para el hilado de diferentes tipos de fibras de origen animal o vegetal. Su función es facilitar la tarea del hilado (conversión de una fibra discontinua en un producto continuo), al aumentar la duración del giro del huso y otorgarle una velocidad más constante. Las materias primas para su elaboración, como así también su morfología, presentan una amplia diversidad descrita en contextos etnográficos y arqueológicos.

Los torteros arqueológicos recolectados en las sierras de Córdoba se caracterizan por la técnica de producción, generalmente basada en la utilización de tiestos cerámicos recortados, regularizados perimetralmente y perforados en el centro, práctica aparentemente común en todas las culturas prehistóricas y antiguas del mundo que cuentan con producción cerámica (Rahmstorf 2015). La manufactura prehispánica de torteros a partir de tiestos de barro cocido, continuó vigente después de la conquista europea hasta las comunidades campesinas subactuales. En menor frecuencia, se han hallado en el área serrana torteros realizados a partir del modelaje y la cocción de arcilla, que presentan diferencias morfológicas con los anteriores. En su mayoría han sido decorados por la técnica de incisión aplicada a la pasta fresca, en forma de cenefa alrededor del mismo, con trazos lineales cardinales, estrellados, sucesión de puntos, figuras geométricas escalonadas o triangulares, generalmente rellenas con puntos o trazos cortos.

La distribución de ambos tipos de artefactos forma parte del problema que proponemos abordar (Figura 1). Así como los torteros reciclados se hallan presentes en numerosos yacimientos arqueológicos de cronología tardía de la provincia de Córdo- ba, los ejemplares modelados proceden de un número reducido de sitios y con una baja densidad de hallazgos respecto a los primeros, con la excepción del sur del Valle de Calamuchita, donde los torteros recuperados corresponden casi exclusivamente al segundo tipo.

Se descarta la posibilidad de que la producción de torteros del primer tipo se deba a la limitación técnica de disponer solo de tiestos, ya que resulta frecuente el hallazgo de este tipo de artefacto junto a otros objetos de cerámica modelada (recipientes, figurinas antropomorfas y zoomorfas, silbatos, cuentas, etc.).

Otros objetos de hueso de forma rectangular, con perforación central y en su mayoría finamente decorados por la técnica de grabado, procedentes de sitios arqueológicos que ocupan los fondos de valles, han sido asociados a torteros (González 1943; Marcellino et al. 1967; Serrano 1945). Sin embargo, debido al reducido número de estos hallazgos y a la posibilidad de que estos artefactos integren otra categoría de objetos (v.g. adornos para vestimentas), no serán considerados en este aporte.

La mayoría de los torteros hallados en la provincia de Córdoba y descritos en la literatura arqueológica, provienen de sitios residenciales y resultan producto de recolecciones superficiales y asistemáticas, aunque se registran algunos ejemplares procedentes de excavaciones estratigráficas (Berberián 1984; González 1943; Pastor et al. 2013; entre otros). También se ha reportado -en baja frecuencia- su hallazgo en aleros rupestres de ocupación transitoria (Argüello de Dorsch 1983; Argüello de Dörsch y Berberián 1985; entre otros). En estos sitios de propósitos especiales, se realizaron tareas de procesamiento elemental como el hilado, de modo que ciertos objetos fueron trasladados hacia alli desde los campamentos residenciales por los usuarios (Nielsen y Roldán 1991).

Este aporte propone indagar, a partir 


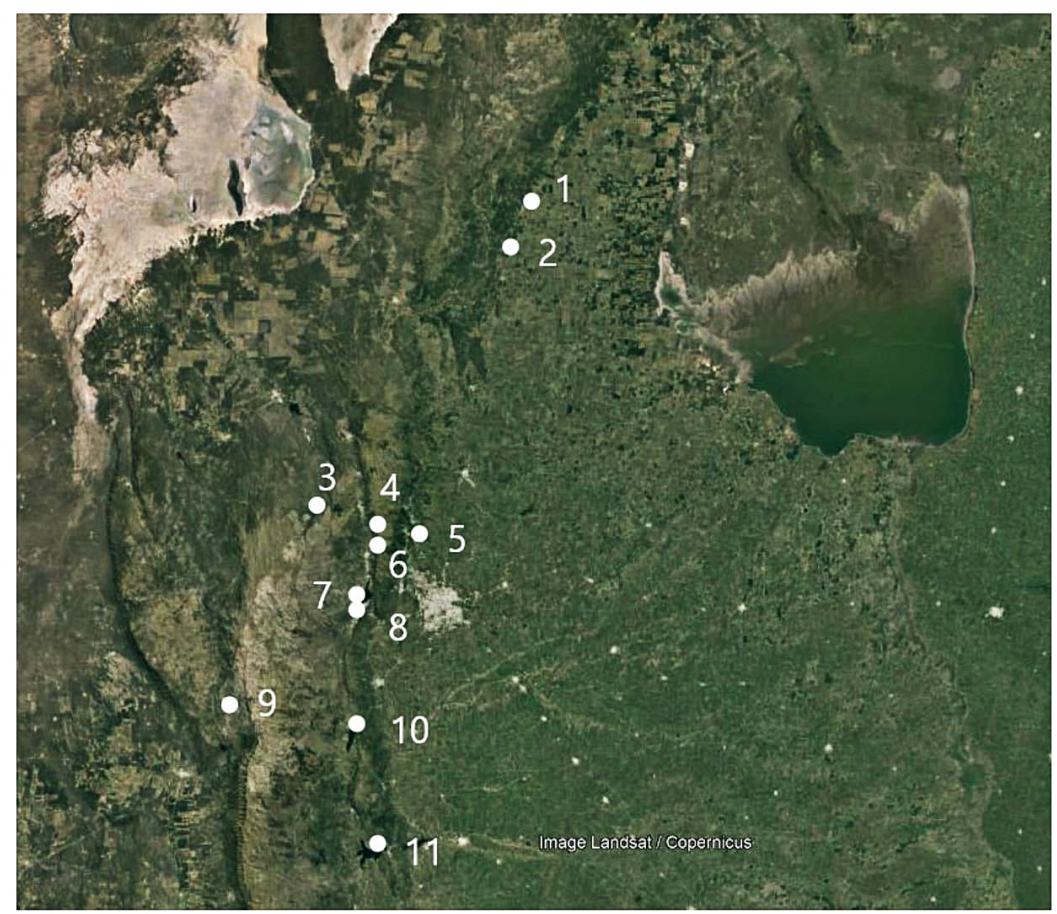

\section{REFERENCIAS:}

Sierras del Norte (SN): 1-Cerro Colorado (CC); 2- Guayascate (GUA) Punilla Centro (PC):3-Pampa de Oláen (OLA); 4-Villa Giardino (VG) y Alto Miéres (AM); 6-Cosquín (COS) - Sierras Chicas (SCH): 5-Río Ceballos (RC) Punilla Sur (PS): 7- San Roque (SR); 8- Cuesta Blanca (CB) - Traslasierra Sur" (TS): 9- Achalita (ACH) - Calamuchita Norte (CN): 10- Potrero de Garay (PG) - Calamuchita Sur (CS): 11- Villa Rumipal (VR) y Embalse (EMB)

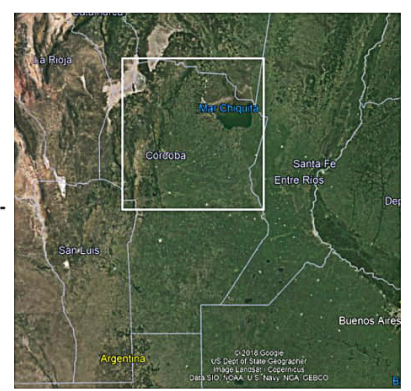

Figura 1. Ubicación de sitios arqueológicos de procedencia de la muestra

del análisis tecnológico y funcional de un conjunto de torteros, si las diferencias entre los artefactos reciclados y modelados se limitan a variaciones de carácter morfológico, o también permiten distintas posibilidades para el procesamiento de fibras textiles. A su vez, se avanza en un estudio comparativo que permita profundizar la variabilidad interna que se registra dentro de los conjuntos que incluyen a ambos tipos.

A partir del trabajo pionero de Parsons (1972) en Mesoamérica ${ }^{1}$, surgió un número creciente de estudios tecnológicos y funcionales sobre contrapesos para el huso de diferentes momentos y lugares alrededor del mundo. En Argentina, los estudios referidos a sus rasgos tecnológicos y morfo- 
lógicos son escasos (Mulvany et al. 1992; Soria 1999; Williams 1983; entre otros). Respecto a los aspectos vinculados a la funcionalidad de estos artefactos, tema al que se refiere esta investigación, los aportes son aún más escasos, donde hasta ahora se destacan los trabajos de López Campeny (2011-2012, 2016), sobre torteros provenientes de la provincia de Santiago del Estero. Con respecto a la arqueología de la provincia de Córdoba, hasta el momento no se han desarrollado análisis tecnológicos de estos artefactos, sin embargo, algunas contribuciones del siglo pasado exponen descripciones morfológicas e iconográficas, como el aporte de González (1943) a cerca de un conjunto de torteros procedentes de Villa Rumipal (sur del Valle de Calamuchita), quien sugirió la similitud en el diseño de algunos ejemplares con torteros del NOA, o bien las estimaciones cronológicas propuestas por Serrano (1945) para estos artefactos, en base a la técnica de producción.

Los torteros incluidos en este aporte -algunos provenientes de recolecciones propias y posteriormente cedidas a colecciones museográficas- carecen de dataciones absolutas. Sin embargo para la mayoría de los ejemplares conocemos los sitios de procedencia, cuyos contextos resultan compatibles con el denominado Período Prehispánico Tardío para la región (ca. 1450-550 AP). En la descripción dada por Serrano (1945:207) sobre los torteros de Córdoba, el autor sugirió que los ejemplares reciclados a partir de tiestos, se adscriben a momentos del contacto hispano-indigena y se vinculan a una industria textil temprano-colonial. Dicha hipótesis, carente de contextos cronológicos, se fundamenta en el criterio de que una confección fácil y poco cuidada, resultaría más acorde a las necesidades de una producción mercantilista que a una lógica de producción no acumulativa, ligada a una labor de mayor costo, de modo que sólo los torteros de cerámica modelados serían de manufactura prehispánica. Para proponer esta diacronía entre ambos conjuntos, dicho autor señala la ausencia de diferencias entre los torteros reciclados de origen arqueológico y aquellos contemporáneos que observó en las áreas rurales de la provincia de Córdoba, sin considerar la continuidad de una tradición tecnológica basada en la reutilización de tiestos como materia prima para confeccionar estos artefactos.

Acerca de los aspectos funcionales basados en las características técnicas de los torteros, existe una diversidad de criterios, cuya complejidad aumenta al contrastar la información etnográfica con los vestigios arqueológicos. Sin embargo, a partir de determinadas variables los estudios tecnológicos pueden proporcionar información, en algunos casos sobre las características de la fibra procesada, en otros, acerca del producto obtenido.

En los estudios sobre los torteros arqueológicos del área mesoamericana, donde las materias primas predominantes en la industria textil prehispánica fueron el algodón (Gossypium sp.) y el magüey (Agave sp.), los primeros autores coinciden en que el peso y secundariamente el diámetro resultan factores críticos para estimar el tipo de fibra procesado. En ese sentido los artefactos grandes y pesados han sido vinculados al procesamiento del magüey, en tanto que aquellos livianos y de menores dimensiones, al del algodón. En base a evidencias provenientes de contextos residenciales excavados, torteros con pesos y diámetros inferiores a $30 \mathrm{~g}$ y $4 \mathrm{~cm}$ respectivamente, generalmente fueron utilizados para el hilado de este último tipo de fibra (Parsons 1972; Smith y Hirth 1988:350; Beaudry Corbett y McCafferty 2002, citados en McCafferty y McCafferty 2008:149150).

Respecto al estudio de los torteros arqueológicos recuperados en la región de los Andes Centrales, donde las fibras tex- 
tiles mayormente difundidas fueron el algodón y el pelo de camélidos (procedentes de diferentes pisos ecológicos), se han intentado asociaciones de este tipo (Conlee y Vaughn 1999, citado en Conlee 2000:345). Torteros hallados en Pirincay (Ecuador), con pesos superiores a $10 \mathrm{~g}$ y diámetros entre 2 y $9 \mathrm{~cm}$, fueron recuperados en contextos asociados a camélidos (Bruhns 1988, citado en Guinea Bueno 2004:76). En tanto que torteros pequeños con pesos y diámetros menores a $11 \mathrm{~g} \mathrm{y} 3 \mathrm{~cm}$ respectivamente, exponen restos de fibras de algodón en el orificio destinado al huso, o bien fueron encontrados con husos y fragmentos de ovillos de esta fibra, integrando canastas textiles (Bird 1979; Conlee 2000:346; Millaire 2008). Sin embargo, esta asociación no resulta concluyente, ya que Bruhns (1988, citado en Guinea Bueno 2004:76), también observó en Pirincay el uso etnográfico de torteros de $12 \mathrm{~g}$ y 3 $\mathrm{cm}$ de diámetro para el hilado de lana de camélido. En otro caso, Splitstoser (2009) comprobó en base a contextos asociados que en el sitio Cerrillos, Valle del Ica (Perú), los torteros utilizados tanto para hilar algodón como fibra de camélido, tenían un peso promedio de $6 \mathrm{~g}$. Estos registros sugieren que torteros de medidas y pesos similares fueron utilizados para procesar distintos tipos de fibras.

En Argentina, los textiles de origen arqueológico se componen generalmente de hilos de camélidos, pertenecientes a especies silvestres y domesticadas. Para la llanura santiagueña (Centro Oeste de Argentina), López Campeny (2011-2012) realizó el primer análisis tecnológico de un conjunto de torteros con pesos de 5-15 g y diámetros de $2-5 \mathrm{~cm}$, quien comprobó la presencia de fibras de algodón en el sedimento adherido al orificio central y surco lateral de un tortero proveniente del sitio arqueológico Sequia Vieja (López Campeny 2016). Sin embargo, aún no se cuenta con evidencia firme a cerca de la utilización de esta materia prima en momentos prehispánicos (Lema y Capparelli 2007).

En este sentido, una discusión más pertinente con el problema que se desea abordar en este aporte, se refiere a la incidencia que puede tener el peso y tamaño de los torteros cuando están involucrados en el procesamiento de un mismo tipo de fibra, o bien cuando se desconoce la materia prima utilizada. En ambos casos se han propuesto dos relaciones: dichas variables se vinculan con el rango de la fibra que se desea procesar, o bien con las características del producto obtenido (hilo).

Respecto a la primera relación, análisis técnicos llevados a cabo en ensayos experimentales sugieren que, así como un peso insuficiente dificulta el estiramiento de las fibras más tenaces o de mayor grosor durante el hilado, un tortero pesado provoca la ruptura de las fibras más cortas y delgadas (Barber 1991; Grömer 2005; Loughran-Delahunt 1996). Según Barber (1991:52) la lana fina puede hilarse con torteros de ca. $8 \mathrm{~g}$, mientras que la lana mediana y gruesa requiere ejemplares ligeramente más pesados y hasta $33 \mathrm{~g}$.

Un valor que permite ponderar el desempeño de estos artefactos, se refiere al cálculo del momento de inercia (I) o la capacidad que tienen los mismos de mantener el movimiento giratorio en el tiempo. Una mayor inercia, entonces, sería aquella que le permite al huso mantener una velocidad constante durante un tiempo más prolongado. Los experimentos realizados por Hochberg (1980:40, citado en Loughran-Delahunt 1996:18), sugieren que un giro rápido resulta más adecuado para fibras ligeras, en tanto que un giro lento es más apropiado para fibras de mayor grosor. Las fibras más tenaces y de mayor grosor requieren una inercia elevada para poder procesarse, mientras que para las fibras más delgadas se requieren giros más rápidos (Sauvage 2013:199).

Respecto a la segunda relación, diver- 
sos autores proponen que la variabilidad en el peso de los torteros, influye en el diámetro del producto obtenido -hilo- (Andersson y Batzner 1999:24-25; Brumfiel 1996; Carpenter et al. 2012:386; Chase et al. 2008; McCafferty y McCafferty 2000:4546; Parsons 1972). Los experimentos de hilados con réplicas de torteros arqueológicos modelados, de morfología cónica y bicónica efectuados por Martensson et al. (2006a), permitieron evidenciar la relación propuesta entre peso y producto obtenido. Para un mismo tipo de lana, los ejemplares de $8 \mathrm{~g}$ produjeron hilos cuyo peso osciló entre 0,06 y $0,12 \mathrm{~g} / \mathrm{m}$, en tanto que con torteros de $18 \mathrm{~g}$, el peso de los hilos producidos midió entre 0,1 y $0,24 \mathrm{~g} / \mathrm{m}$.

Experimentos realizados por Grömer (e.g. 2005:110) con torteros arqueológicos, procedentes de Austria (Europa central), sobre dos conjuntos caracterizados por diferentes rangos de peso y aplicados al procesamiento de la lana, también aportan información sugerente. El primer conjunto, recuperado en Meidling y correspondiente al Neolítico Tardio, reúne ejemplares de peso considerable (120-140 g), en tanto que el segundo conjunto, procedente de Hallsttat, sitio de la temprana Edad del Hierro, integra ejemplares con pesos entre 8 y 20 g. A partir de los torteros del primer conjunto se obtuvieron hilos con un diámetro entre 0,7 y $2 \mathrm{~mm}$, aunque los mejores resultados produjeron hilos entre 0,8 y $1,5 \mathrm{~mm}$, mientras que con aquellos del segundo conjunto, los mejores resultados se dieron con hilos finos entre 0,2 y 0,7 $\mathrm{mm}$. Los experimentos concluyen que con torteros de peso menor a $20 \mathrm{~g}$ no pueden obtenerse hilos de diámetro mayor a 1,5 $\mathrm{mm}$.

Otros experimentos sugieren que diferencias de peso aún menores se requieren para obtener resultados de este tipo, ya que variaciones entre 5 y $10 \mathrm{~g}$ resultan suficientes para modificar el diámetro del hilo producido por un tortero (Lundin 2016).
El diámetro del orificio central, indicador indirecto del tamaño del huso, resulta otra variable que puede aportar información relativa sobre el tamaño del eje (Hernández y Peniche 2012; Kossowska-Janik 2016; McCafferty y McCafferty 2008:145; Sauvage 2013), como así también sobre las características de las fibras que estos artefactos admiten y el espesor del hilo obtenido (López Campeny 2016:127; McCafferty y Mc Cafferty 2000:45-46; Parsons 1972).

Respecto al tipo de materias primas implicado en la utilización de estos artefactos, las condiciones ambientales presentes en el área de estudio han impedido la conservación de textiles, de modo que no contamos con evidencias materiales sobre las fibras utilizadas en su confección. El registro arqueológico expone, a parte de los torteros, fragmentos y recipientes cerámicos con marca de redes y artefactos óseos que pueden ser vinculados al complejo textil (v. g. agujas, huesos planos de extremos aguzados, peines, etc.). Una vía de indagación lo constituyen algunas fuentes etnohistóricas tempranas, donde se menciona la utilización de fibra de origen animal (camélidos) para la confección de vestimentas. En la denominada Relación Anónima, se señala que los pobladores locales "traen todos los más en las ticas de las cabeza y tocados, que de lana hacen..." o bien: "las camisetas que traen vestidas son hechas de lana...", y más adelante: "crian mucho ganado de la tierra y danse por ello por las lanas de que se aprovechan" (Berberián 1987[1572]:227). En otro documento, la Relación de las Provincias de Tucumán de Pedro Sotelo de Narváez, dice que "es gente que de su natural se vestía de lana de ganado del Pirú, que tienen alguno, aunque más pequeño..." (Berberián 1987[1582-3]:242). Otro autor, Cieza de León, también hace alusión al uso de fibra animal al decir: "de verano traen unas camisetas no muy largas $y$ de invierno mantas complidas de lana 
basta; las mujeres andan vestidas desta ropa" (Tercero libro de las guerras civiles del Perú. Historiadores de Indias II, Madrid 1909: 247, citado en González 1943:38).

Si bien las crónicas locales constituyen una base para sugerir prácticas pastoriles (Berberián y Roldán 2003), los estudios osteométricos nos obligan a ser cautos respecto a esta posibilidad, y a considerar los artefactos inherentes a la industria textil, por ahora vinculados al procesamiento de fibras de guanaco (lama guanicoe) (Medina et al. 2014). Hasta el momento no se cuenta con otro tipo de información, sin embargo la ausencia de menciones sobre otras fibras textiles utilizadas en el pasado de Córdoba, no descartan su utilización.

\section{Materiales y método}

La muestra incluida en este trabajo reúne 164 torteros de cerámica, provenientes de distintos reservorios de las provincias de Córdoba y Buenos Aires (Tabla 1). Desde un criterio tecnológico (v.g. producción), la totalidad de estos artefactos puede agruparse en dos conjuntos bien definidos. El grupo I (136 elementos) reúne los ejemplares manufacturados a partir del reciclado de tiestos; en este caso, recortes de forma circular o sub-circular, de escaso espesor y sección plana (Figura 2). Para este fin se seleccionaron fragmentos cerámicos cuya curvatura apenas resulta perceptible. La distribución espacial de este grupo ocupa casi toda el área de las sierras de Córdoba. Si bien este tipo de tortero carece de decoración, en dos ejemplares procedentes del sur del Valle de Punilla, observamos que los tiestos utilizados incluían parte de la decoración incisa de los recipientes originales. En ambos casos se trata de figuras triangulares rellenas de puntos, diseño frecuente en la iconografia de recipientes cerámicos observada en el área. Un caso particular está representado por dos ejemplares identificados en la localidad arqueológica Cerro Colorado (sierras del Norte), reciclados a partir de tiestos pintados de procedencia alóctona (v.g. llanura santiagueña) (Figura 3).

El grupo II (28 elementos) integra los torteros modelados, en su mayoría decorados por incisión, de forma circular pero de sección variable (acampanada, troncocónica, elíptica, rectangular, etc.: Figura 4). Su distribución espacial, más acotada, no es ajena al patrón detectado para el consumo y producción de imágenes visuales sobre el arte mueble en general, donde los hallazgos provienen en su totalidad de áreas consideradas como de colonización arraigada $^{2}$ (Pastor y Tissera 2016). La representatividad de este conjunto expone diferencias que merecen ser atendidas. Por

\begin{tabular}{|c|c|c|c|c|}
\hline \multirow{2}{*}{ RESERVORIO } & \multirow{2}{*}{ CÓDIGO } & \multirow{2}{*}{ LOCALIDAD } & \multicolumn{2}{|c|}{ EJEMPLARES } \\
\hline & & & TIPO I & TIPO II \\
\hline Museo Numba Charava & MNC & Villa Carlos Paz & 63 & 12 \\
\hline Museo Camin Cosquín & MCC & Cosquín & 28 & 0 \\
\hline Museo Cerro Colorado & MACC & Cerro Colorado & 9 & 0 \\
\hline Museo Regional Camiare & MARC & Almafuerte & 3 & 9 \\
\hline Museo Municipal & MAM & Alta Gracia & 28 & 0 \\
\hline Museo Gunisacate & MG & Las Peñas & 5 & 1 \\
\hline Museo Universidad de La Plata & UNLP & La Plata & 0 & 6 \\
\hline TOTAL & & & 136 & 28 \\
\hline
\end{tabular}

Tabla 1. Repositorios museológicos de las colecciones incluidas 


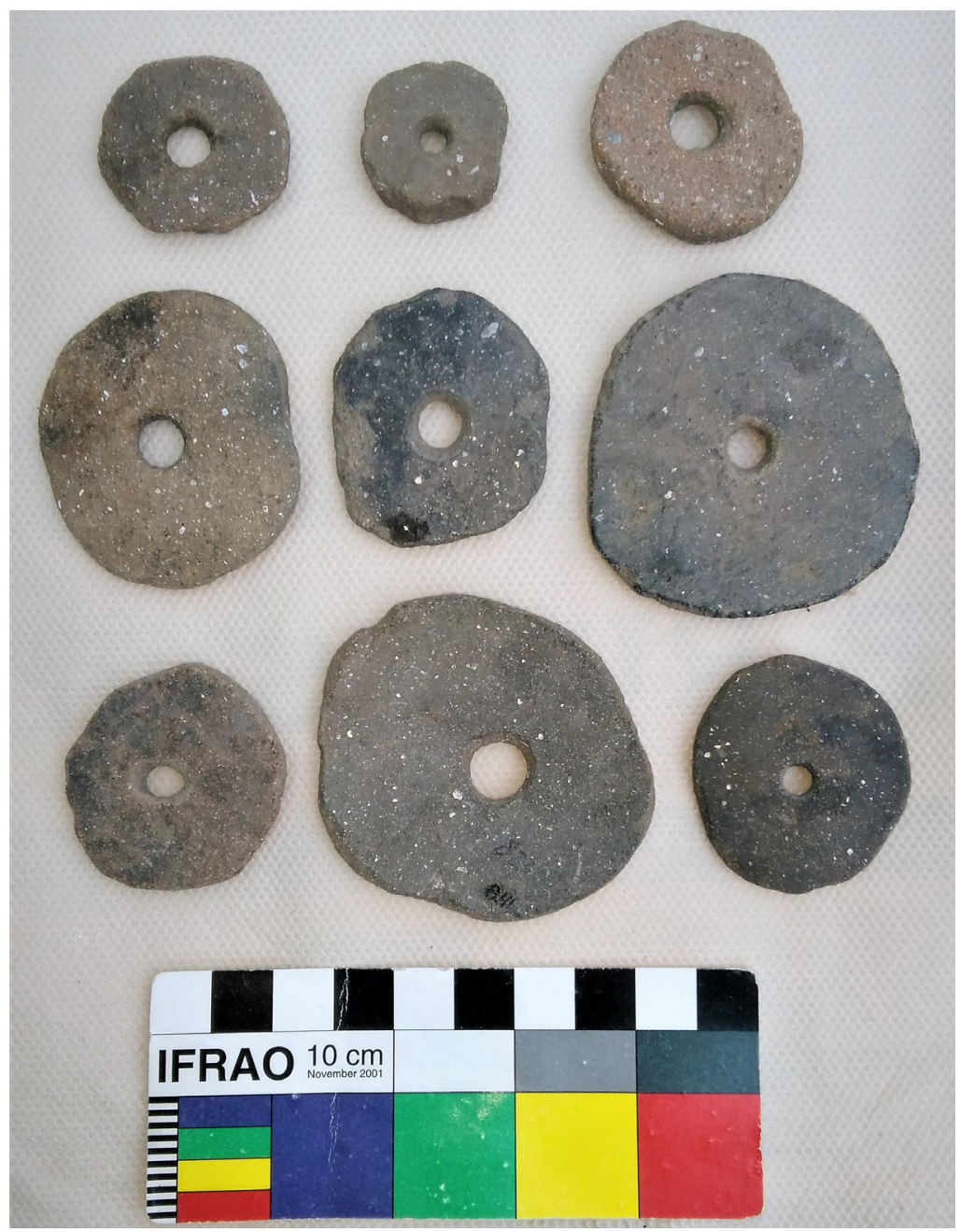

Figura 2. Torteros reciclados del Tipo I.

ejemplo, en el número de ejemplares provenientes de la localidad arqueológica San Roque (sur del Valle de Punilla), se observa un amplio predominio del grupo I, que ocupa el $85,53 \%$ de la muestra, sobre el grupo II, que reúne el $14,47 \%$ restante, relación que también se verifica en otras áreas geográficas donde se han hallado artefactos de ambos grupos. En cambio, en los sitios arqueológicos incluidos en el área del Embalse, en la cuenca media/alta del río Tercero (sur del Valle de Calamuchita) se observa la relación inversa, con el 18,75 $\%$ de la muestra contenida en el primer grupo y el 81,25 \% en el segundo ${ }^{3}$. El predominio de ejemplares modelados sobre reciclados observado en el área de Embalse, presente en las colecciones como en las 


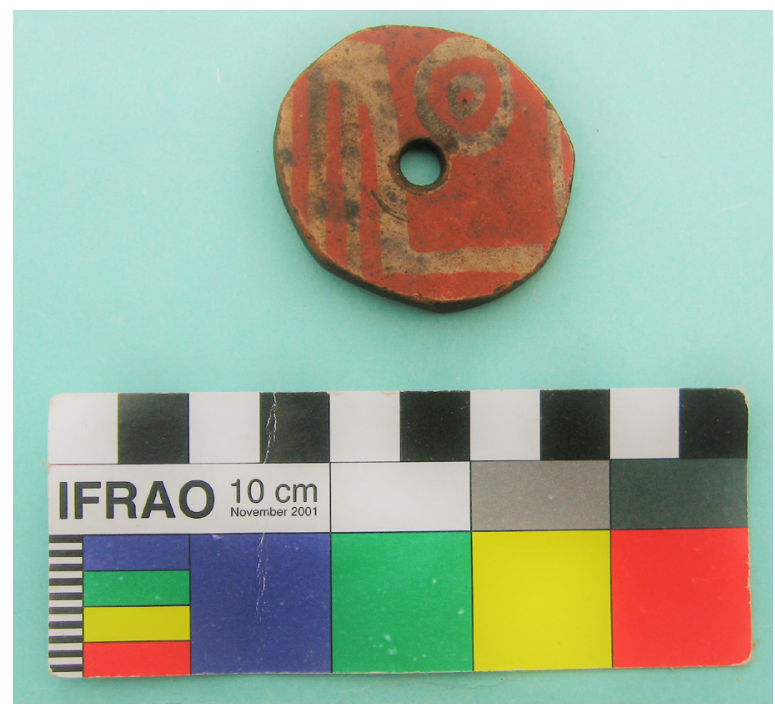

Figura 3. Ejemplar del primer tipo proveniente de Cerro Colorado, hallado por el autor. Compatible con la estilistica Averías-Yokavil rojo sobre blanco (Taboada comunicación personal, 2017).

fuentes bibliográficas, no tiene hasta ahora correlato con ningún otro sitio de Córdoba. Otro caso se registra en determinados sitios arqueológicos, que si bien se sitúan dentro del área de producción y consumo del arte mueble decorado (Pastor y Tissera 2016), la totalidad de los torteros recuperados exponen la ausencia de ejemplares del grupo II. En esta casuística se incluyen dos sitios: el primero es Alto Mieres (norte del Valle de Punilla), con recolecciones de cerámicos decorados provenientes de excavaciones asistemáticas y donde, la abundante presencia de figurinas antropomorfas motivó a los aficionados a denominarlo "Loma de las Estatuillas". El segundo, de connotaciones similares, es Potrero de Garay (Berberián 1984), con el hallazgo de numerosas figurinas antropomorfas y cerámicos decorados.

Estas observaciones permiten detectar un patrón de distribución más amplio para los torteros del grupo I, los que ocupan ex- tensamente el área serrana de la provincia de Córdoba, en tanto que para el grupo II, se observa una distribución espacial más acotada respecto al primer conjunto, con un predominio significativo en un área delimitada espacialmente.

Para evaluar la funcionalidad de estos objetos, se ponderaron cuatro variables mensurables: el diámetro exterior, el peso, el diámetro del orificio central y el espesor como un modo de determinar la inercia de la rotación e inferir el tamaño aproximado del huso. Para estimar el peso original de los torteros incompletos, se dividió el peso del fragmento existente (p) por el porcentaje remanente $(R)$ sobre $100(p /[R / 100])$.

Para asignar un diámetro estimado a los torteros incluidos en el grupo I, donde el recorte de algunas piezas muestra un perimetro levemente irregular, se consideró el promedio entre el radio mínimo y máximo del disco. Los diámetros obtenidos varian entre 2 y $6,6 \mathrm{~cm}$, con una mayor 


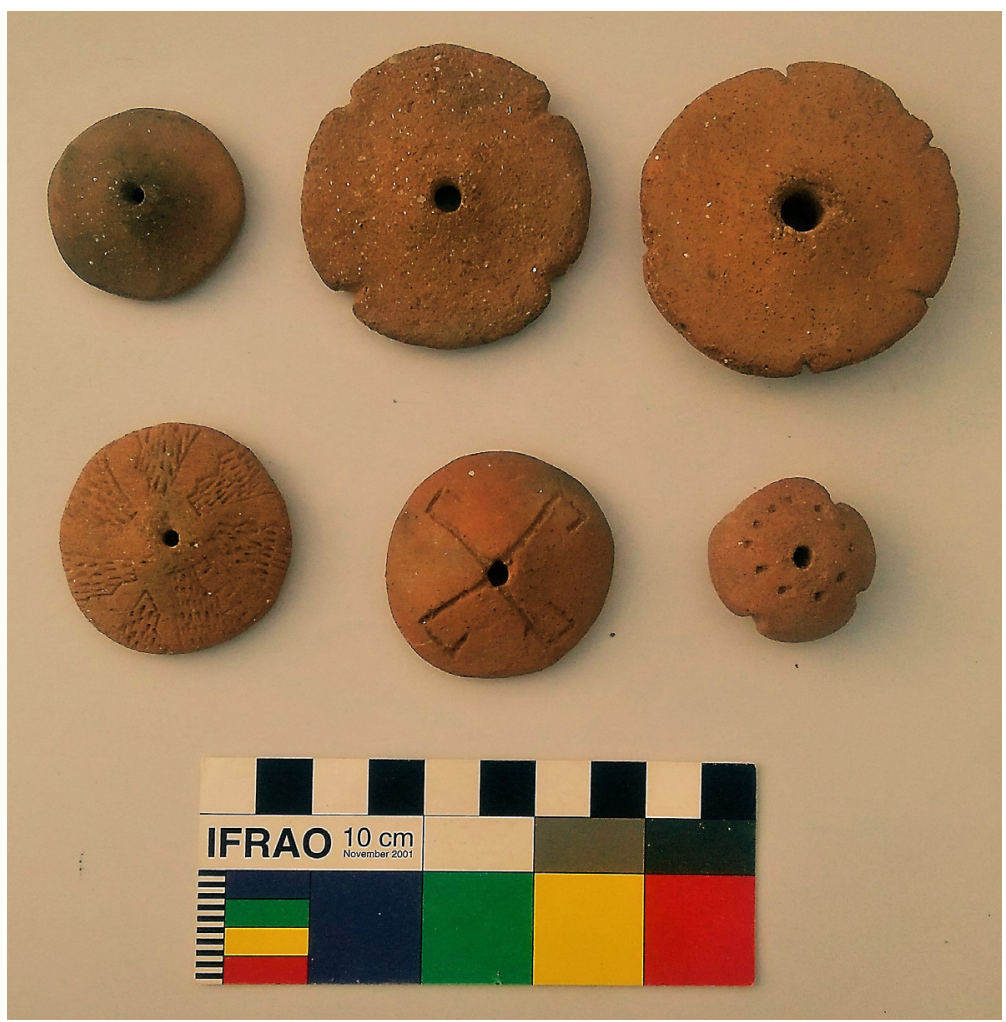

Figura 4. Torteros modelados del Tipo II.

concentración entre 3 y $5 \mathrm{~cm}(80,30 \%)$. Este predominio de valores diametrales en ese rango, indica una marcada estandarización en el recorte de tiestos para la confección de torteros. Para el grupo II el diámetro de los discos oscila entre 1,7 y $5,7 \mathrm{~cm}$, donde el $62,07 \%$ se agrupa en el rango $3-5 \mathrm{~cm}$, en tanto que el $27,58 \%$ en valores inferiores a $3 \mathrm{~cm}$.

En la muestra examinada, la segunda variable correspondiente al peso para el grupo I oscila entre 2,77 y $48,2 \mathrm{~g}$, donde el $43,93 \%$ de los artefactos presenta valores menores a $10 \mathrm{~g}$, en tanto que el $40,14 \%$ se agrupa en el rango 10-20 g. Dicha variable para el grupo II oscila entre 3,03 y 45,8 g y de acuerdo a las mediciones, los ejempla- res cuyos pesos se incluyen en el rango 10 20 g ocupan el 75,86 \% de este conjunto.

Otro variable considerada es el diámetro del orificio central para soportar el huso, cuyo rango para el primer grupo oscila entre 0,3 y $0,9 \mathrm{~cm}$, con una alta concentración entre 0,4 y 0,7 cm (90,34\%), en tanto que para el segundo grupo, el 79,77 $\%$ de los artefactos acusan valores que no superan los $0,4 \mathrm{~cm}$.

La última variable se refiere al espesor. En el grupo I la misma está dada por la sección de los tiestos utilizados para su manufactura, conformando un rango altamente estandarizado, con valores predominantes entre 0,5 y $0,7 \mathrm{~cm}(91,42 \%)$. En el segundo grupo cuyo espesor generalmen- 
te no resulta constante, la altura entorno al orificio central, que representa el valor máximo de la sección, oscila entre $0,5 \mathrm{y}$ $1,96 \mathrm{~cm}$, donde el $75 \% \geq 1$ y el $25 \%<1$.

La información de cada tortero, junto a las cuatro magnitudes medidas, fue incluida en una planilla Excel conformando una fila, donde cada columna expone el rango completo de una de las cuatro variables. Se seleccionaron alternativamente distintos pares de variables de ambos conjuntos y se aplicó el coeficiente de correlación de Pearson (r) para calcular matemáticamente su relación de covariación. Los resultados obtenidos posibilitaron medir la magnitud de la relación entre dos variables lineales $\left(r^{2}\right)$ y en algunos casos establecer el grado de dependencia entre ambas. Por ejemplo, dicho coeficiente aplicado a la ratio entre el diámetro del disco y el peso de los torteros mostró una fuerte correlación positiva entre ambos $(r=0,8912)$, con una variabilidad explicada del $79 \%$ para el grupo I. Es decir, que ese porcentaje de individuos presentan una relación directa entre ambas variables, de modo que al aumentar el diámetro lo hace correlativamente el peso. Esto significa que para incidir en el peso de los torteros reciclados la variable que el productor manejó es el diámetro de los discos, algo esperable considerando la marcada estandarización del espesor de los tiestos, la que resulta una variable ajena a la manipulación.

Para el segundo grupo se observaron diferencias en las relaciones de covariación entre los torteros provenientes del sur de Punilla y aquellos del sur de Calamuchita, áreas que reúnen el mayor número de la muestra, lo que amerita tratar por separado cada sub-conjunto. La covarianza entre el peso y el diámetro de los torteros de $\mathrm{Pu}$ nilla $(\mathrm{r}=0,8445)$ muestra una correlación positiva del $70 \%$, mientras que para el área de Calamuchita es marcadamente inferior $(r=0,4973)$, con una débil correlación positiva del $24 \%$. Esto significa que en los tor- teros provenientes del sur de Calamuchita los productores ponderaron mayormente la altura para obtener el peso deseado, y en menor medida el diámetro, variable qué en cambio, fue determinante entre los productores del sur de Punilla.

Las covarianzas diámetro perimetral/espesor y diámetro orificio central/ diámetro perimetral para ambos grupos, resultan muy bajas o cercanas a cero, lo que implica que ambos pares de variables son independientes.

El momento de inercia, calculado en base al peso y al diámetro de los torteros, permitió discernir las performances vinculadas a cada grupo en general. Para especímenes de espesor uniforme, en este caso la totalidad de los incluidos en el grupo I y aquellos del grupo II de sección plana o rectangular, se aplicó la fórmula utilizada para cuerpos geométricos cilindricos, $\mathrm{I}=1 / 2 \mathrm{MxR}^{2}$, donde $\mathrm{M}$ es el peso del disco y $\mathrm{R}$ es el radio (Chmielewski y Gardynski 2010; Loughran-Delahunt 1996).

En el caso de los cuerpos con morfología irregular, como ocurre con la mayoría de los torteros del grupo II, el cálculo se dificulta ya que no pueden reducirse fácilmente a sólidos ideales, por lo tanto, las especificaciones técnicas limitadas a la masa y el diámetro no resultan suficientes para calcular el momento de inercia utilizando fórmulas generales (Chmielewski y Gardynski 2010). Sin embargo, en aquellos ejemplares de sección troncocónica, puede aplicarse la fórmula adaptada $\mathrm{I}=3 / 10 \mathrm{MxR}^{2}[(4 \mathrm{to}+\mathrm{ti}) /(2 \mathrm{to}+\mathrm{ti})]$, donde to es el espesor del borde y ti el espesor entorno al orificio central (Tipler 1982:268 en Loughran-Delahunt 1996:17).

Los resultados obtenidos expusieron un valor de I entre 1,74 y 262,44 g/ $\mathrm{cm}^{2}$ para el primer grupo, mientras que para los ejemplares de sección rectangular y troncocónica pertenecientes al segundo grupo, los valores se reducen a un rango entre 1,83 y $89,67 \mathrm{~g} / \mathrm{cm}^{2}$. 


\begin{tabular}{|c|c|c|c|c|c|c|c|c|c|}
\hline $\begin{array}{l}\text { REPOSI- } \\
\text { TORIO }\end{array}$ & $\begin{array}{l}\text { PESO } \\
\text { (g) }\end{array}$ & $\begin{array}{l}\text { DIÁMETRO } \\
\text { (cm) }\end{array}$ & $\begin{array}{l}\text { INERCIA } \\
\left(\mathrm{g} / \mathrm{cm}^{2}\right)\end{array}$ & $\begin{array}{l}\text { PROCE- } \\
\text { DENCIA }\end{array}$ & $\begin{array}{c}\text { REPOSI- } \\
\text { TORIO }\end{array}$ & $\begin{array}{l}\text { PESO } \\
\text { (g) }\end{array}$ & $\begin{array}{l}\text { DIÁMETRO } \\
\text { (cm) }\end{array}$ & $\begin{array}{c}\text { INERCIA } \\
\left(\mathrm{g} / \mathrm{cm}^{2}\right)\end{array}$ & $\begin{array}{l}\text { PROCE- } \\
\text { DENCIA }\end{array}$ \\
\hline MCC-12 & 2,77 & 3,2 & 3,54 & $\mathrm{AM}(\mathrm{PN})$ & MNC-024 & 6,97 & 3 & 7,84 & SR (PS) \\
\hline MNC-053 & 2,88 & 2,2 & 1,74 & SR (PS) & MAM-53 & 7 & 3,3 & 9,52 & PG $(\mathrm{CN})$ \\
\hline MCC-5 & 3,64 & 2,5 & 2,84 & $\mathrm{AM}(\mathrm{PN})$ & MNC-015 & 7,12 & 3,25 & 9,4 & SR (PS) \\
\hline MNC-009 & 4 & 2 & 2 & SR (PS) & MNC-032 & 7,14 & 3,25 & 9,42 & SR (PS) \\
\hline MACC-1 & 4,05 & 2,3 & 2,71 & $\mathrm{CC}(\mathrm{SN})$ & MNC-022 & 7,16 & 3,1 & 8,6 & SR (PS) \\
\hline MNC-038 & 4,16 & 2,4 & 2,99 & SR (PS) & MNC-029 & 7,23 & 3,35 & 10,17 & SR (PS) \\
\hline MNC-055 & 4,21 & 2,7 & 3,82 & SR (PS) & MNC-017 & 7,36 & 3,2 & 9,42 & SR (PS) \\
\hline MNC-033 & 4,49 & 2,55 & 3,65 & SR (PS) & MCC-10 & 7,61 & 3,5 & 11,94 & $\mathrm{AM}(\mathrm{PN})$ \\
\hline MAM-44 & 4,98 & 3,1 & 5,98 & PG (CN) & MAM-54 & 7,72 & 3,3 & 10,5 & PG (CN) \\
\hline MNC-040 & 5,24 & 2,6 & 4,42 & SR (PS) & MNC-054 & 7,74 & 3,8 & 13,97 & SR (PS) \\
\hline MNC-034 & 5,24 & 2,65 & 4,59 & SR (PS) & MNC-012 & 7,76 & 3 & 8,73 & SR (PS) \\
\hline MNC-035 & 6,04 & 2,9 & 6,34 & SR (PS) & MNC-026 & 8 & 3,7 & 13,69 & SR (PS) \\
\hline MARC-10 & 6,19 & 3,05 & 7,19 & EMB (CS) & MNC-010 & 8,26 & 3,25 & 10,9 & SR (PS) \\
\hline MNC-036 & 6,24 & 2,95 & 6,78 & SR (PS) & MNC-074 & 8,28 & 3 & 9,31 & SR (PS) \\
\hline MG-1 & 6,27 & 2,8 & 6,14 & GUA (SN) & MARC-11 & 8,4 & 3 & 9,45 & EMB (CS) \\
\hline MCC-23 & 6,37 & 3,05 & 7,4 & $\mathrm{AM}(\mathrm{PN})$ & \begin{tabular}{|l|} 
MNC-043 \\
\end{tabular} & 8,48 & 3,6 & 13,73 & SR (PS) \\
\hline MACC-124 & 6,4 & 2,7 & 5,83 & $\mathrm{CC}(\mathrm{SN})$ & \begin{tabular}{|l|} 
MNC-028 \\
\end{tabular} & 8,51 & 3,1 & 10,22 & SR (PS) \\
\hline MNC-039 & 6,46 & 3,2 & 8,26 & SR (PS) & MAM-56 & 8,51 & 3,7 & 14,56 & PG (CN) \\
\hline MG-5 & 6,7 & 3,1 & 8,04 & GUA (SN) & MCC-11 & 8,59 & 3,4 & 12,42 & $\mathrm{AM}(\mathrm{PN})$ \\
\hline MCC- 20 & 6,76 & 3,4 & 9,76 & $\mathrm{AM}(\mathrm{PN})$ & \begin{tabular}{|l|} 
MG-3 \\
\end{tabular} & 8,68 & 3,1 & 10,42 & GUA (SN) \\
\hline MAM-76 & 6,82 & 3,45 & 10,14 & PG $(\mathrm{CN})$ & MG-2 & 8,72 & 3,55 & 13,73 & GUA (SN) \\
\hline MAM-60 & 6,9 & 3,4 & 9,97 & PG (CN) & MCC-21 & 8,91 & 3,5 & 13,64 & $\mathrm{AM}(\mathrm{PN})$ \\
\hline MNC-078 & 6,94 & 3,3 & 9,44 & SR (PS) & MNC-027 & 8,93 & 3,45 & 13,28 & SR (PS) \\
\hline
\end{tabular}

Tablas 2. Características técnicas de los torteros reciclados (1)

De acuerdo a los datos medidos, los torteros reciclados de la muestra fueron agrupados en cuatro subconjuntos diferentes: el primero, que reúne los ejemplares con pesos menores a $10 \mathrm{~g}(43,93 \%)$, diámetros generalmente hasta $4 \mathrm{~cm}$ y momentos de inercia que no suelen superar los $20 \mathrm{~g} /$ $\mathrm{cm}^{2}$ (Tabla 2). Estos torteros más livianos, según los valores inerciales producen giros rápidos y cortos. El segundo subconjunto, reúne los ejemplares entre 10 y $20 \mathrm{~g}(40,14$ $\%$ ), diámetros mayormente entre 4 y $5 \mathrm{~cm}$ y momentos de inercia generalmente entre 20 y $50 \mathrm{~g} / \mathrm{cm}^{2}$ (Tablas 3 y 4). Estos torteros un poco más pesados, producen giros algo más prolongados que los anteriores, facilitando aún más la tarea del hilado al reducir el tiempo de trabajo. Un tercer subconjunto, algo menor, incluye los ejemplares cuyos pesos oscilan entre 20 y $30 \mathrm{~g}(13,46$ \%), diámetros entre 5 y $6 \mathrm{~cm}$ e I=50-113 g/ $\mathrm{cm}^{2}$ (Tabla 4). Estos ejemplares producen giros aún más prolongados y permiten una mayor tracción de las fibras. Por último, un subconjunto minoritario (menor al $2 \%$ ) incluye los ejemplares con pesos que superan los $40 \mathrm{~g}$, diámetros de más de $6 \mathrm{~cm}$ y momentos de inercia mayores a $200 \mathrm{~g} /$ $\mathrm{cm}^{2}$ (Tabla 3).

En los torteros del segundo tipo la variabilidad de pesos presenta una distribución más acotada, donde se registra una marcada concentración en el rango 1020 g $(75,86 \%)$, con diámetros en torno a $3-4,5 \mathrm{~cm}$ y momentos de inercia generalmente entre 10 y $30 \mathrm{~g} / \mathrm{cm}^{2}$ (Tabla 5). En este caso, ejemplares de igual peso que los torteros reciclados presentan un menor momento de inercia, reducido por la ratio altura/diámetro, lo que produce giros más cortos que aquellos. 
Tissera L. - "Una aproximación a los estudios tecnológicos de los torteros indígenas ..."

\begin{tabular}{|c|c|c|c|c|c|c|c|c|c|}
\hline $\begin{array}{l}\text { REPOSI- } \\
\text { TORIO }\end{array}$ & $\begin{array}{l}\text { PESO } \\
\text { (g) }\end{array}$ & $\begin{array}{l}\text { DIÁMETRO } \\
\text { (cm) }\end{array}$ & $\begin{array}{c}\text { INERCIA } \\
\left(\mathrm{g} / \mathrm{cm}^{2}\right)\end{array}$ & $\begin{array}{l}\text { PROCE- } \\
\text { DENCIA }\end{array}$ & $\begin{array}{l}\text { REPOSI- } \\
\text { TORIO }\end{array}$ & $\begin{array}{l}\text { PESO } \\
\text { (g) }\end{array}$ & $\begin{array}{l}\text { DIÁMETRO } \\
\text { (cm) }\end{array}$ & $\begin{array}{c}\text { INERCIA } \\
\left(\mathrm{g} / \mathrm{cm}^{2}\right)\end{array}$ & $\begin{array}{l}\text { PROCE- } \\
\text { DENCIA }\end{array}$ \\
\hline MCC-3 & 8,95 & 3,1 & 10,77 & $\mathrm{AM}(\mathrm{PN})$ & MNC-050 & 11,22 & 4,05 & 23 & SR (PS) \\
\hline MNC-046 & 8,98 & 3,8 & 16,2 & SR (PS) & MNC-081 & 11,24 & 3,7 & 19,23 & SR (PS) \\
\hline MNC-031 & 9,13 & 3,45 & 13,56 & SR (PS) & MCC-18 & 11,26 & 4 & 22,52 & $\operatorname{COS}(\mathrm{PC})$ \\
\hline MNC-049 & 9,2 & 3,7 & 15,74 & SR (PS) & MNC-082 & 11,38 & 4 & 22,76 & SR (PS) \\
\hline MACC-2 & 9,43 & 3,42 & 13,77 & $\mathrm{CC}(\mathrm{SN})$ & MAM-55 & 11,4 & 3,9 & 21,67 & PG (CN) \\
\hline MACC-3 & 9,48 & 3,65 & 15,78 & $\mathrm{CC}(\mathrm{SN})$ & MNC-020 & 11,5 & 4 & 23 & SR (PS) \\
\hline MAM-51 & 9,67 & 4,6 & 25,57 & PG (CN) & MNC-011 & 11,78 & 3,75 & 20,7 & SR (PS) \\
\hline MNC-042 & 9,68 & 3,35 & 13,46 & SR (PS) & MCC-15 & 12,31 & 4,5 & 31,15 & $\mathrm{AM}(\mathrm{PN})$ \\
\hline MAM-77 & 9,72 & 3,5 & 14,88 & PG (CN) & \begin{tabular}{|l|} 
MCC-1 \\
\end{tabular} & 12,32 & 4,1 & 25,88 & $\mathrm{AM}(\mathrm{PN})$ \\
\hline MCC-27 & 9,76 & 3,5 & 14,94 & VG (PC) & MCC-14 & 12,39 & 4,1 & 26,03 & $\operatorname{COS}(\mathrm{PC})$ \\
\hline MARC-12 & 9,83 & 3 & 11,05 & EMB (CS) & MAM-46 & 12,54 & 3,85 & 23,23 & PG (CN) \\
\hline MAM-63 & 9,91 & 3,5 & 15,17 & PG (CN) & MNC-018 & 12,71 & 4,1 & 26,68 & SR (PS) \\
\hline MNC-037 & 9,94 & 4,9 & 29,82 & SR (PS) & MAM-71 & 12,75 & 3,95 & 24,86 & PG (CN) \\
\hline MNC-030 & 9,96 & 3,5 & 15,25 & SR (PS) & MNC-047 & 12,77 & 4,15 & 27,42 & SR (PS) \\
\hline MNC-067 & 10,18 & 3,5 & 15,58 & SR (PS) & MCC-19 & 13,24 & 4,3 & 30,6 & $\mathrm{AM}(\mathrm{PN})$ \\
\hline MAM-68 & 10,29 & 3,7 & 17,6 & PG (CN) & MAM-45 & 13,25 & 5,6 & 51,94 & PG (CN) \\
\hline MAM-78 & 10,38 & 3,9 & 19,73 & PG $(\mathrm{CN})$ & MAM-64 & 13,26 & 4,3 & 30,64 & PG (CN) \\
\hline MAM-69 & 10,43 & 4,1 & 21,91 & PG (CN) & MNC-084 & 13,44 & 4 & 26,88 & SR (PS) \\
\hline MAM-74 & 10,52 & 3,65 & 17,51 & PG (CN) & MACC-35 & 13,48 & 3,7 & 23,06 & $\mathrm{CC}(\mathrm{SN})$ \\
\hline MNC-023 & 10,8 & 3,65 & 17,98 & SR (PS) & MAM-49 & 13,52 & 4,3 & 31,24 & PG (CN) \\
\hline MNC-061 & 10,92 & 4 & 21,84 & SR (PS) & MACC-6 & 13,56 & 4,2 & 29,89 & $\mathrm{CC}(\mathrm{SN})$ \\
\hline MNC-051 & 10,96 & 4,25 & 24,74 & SR (PS) & MNC-064 & 13,62 & 4 & 27,24 & SR (PS) \\
\hline MACC-5 & 11,2 & 4,1 & 23,53 & $\mathrm{CC}(\mathrm{SN})$ & MAM-61 & 13,66 & 4,2 & 14,34 & $\mathrm{PG}(\mathrm{CN})$ \\
\hline
\end{tabular}

Tablas 3. Características técnicas de los torteros reciclados (2)

\section{Discusión y resultados}

En base a los datos presentados: ¿Qué permiten procesar y producir estos artefactos?

En términos tecnológicos, los resultados obtenidos en las mediciones de la muestra posibilitan comparaciones que expongan, tanto las diferencias y similitudes observadas entre ambos grupos tipológicos, como así también la variabilidad interna observada en cada uno de estos.

Si bien, las mediciones del peso registradas para ambos grupos indican correspondencias entre sus valores mínimos y máximos (entre 2,77 y 48,2 g para torteros del primer tipo y entre 3,03 y 45,8 g para los del segundo tipo), los ejemplares reciclados se distribuyen mayormente en los rangos $3-10 \mathrm{~g}$ y $10-20 \mathrm{~g}(84,07 \%$ para ambos), mientras que los modelados se concentran en el segundo ítem $(75,86 \%)$. Si consideramos este último rango, solamente para los ejemplares provenientes del sur del Valle de Calamuchita (de ahora en adelante CS), área donde esta tipología resulta mayoritaria, este porcentaje se eleva a 91,66 \% debido a la ausencia de pesos mayores a 20 g y a la baja frecuencia de artefactos con pesos menores a $10 \mathrm{~g}$, rango que, en cambio resulta ampliamente representado dentro del grupo I (43,93\%).

En términos tecnológicos y funcionales, la información que pueden aportar torteros provenientes de distintos contextos culturales y cronológicos, puede ser contrastada con la información obtenida a partir de artefactos que reúnan parámetros similares (peso, medidas y momentos de inercia) (Chmielewsky y Gardynski 2010).

Como fue señalado anteriormente, experimentos efectuados por Grömer 


\begin{tabular}{|c|c|c|c|c|c|c|c|c|c|}
\hline $\begin{array}{l}\text { REPOSI- } \\
\text { TORIO }\end{array}$ & $\begin{array}{c}\text { PESO } \\
\text { (g) }\end{array}$ & $\begin{array}{l}\text { DIÁMETRO } \\
\text { (cm) }\end{array}$ & $\begin{array}{c}\text { INERCIA } \\
\left(\mathrm{g} / \mathrm{cm}^{2}\right)\end{array}$ & $\begin{array}{l}\text { PROCE- } \\
\text { DENCIA }\end{array}$ & $\begin{array}{l}\text { REPOSI- } \\
\text { TORIO }\end{array}$ & $\begin{array}{l}\text { PESO } \\
\text { (g) }\end{array}$ & $\begin{array}{c}\text { DIÁMETRO } \\
\text { (cm) }\end{array}$ & $\underset{\left(\mathrm{g} / \mathrm{cm}^{2}\right)}{\operatorname{INERCIA}}$ & $\begin{array}{l}\text { PROCE- } \\
\text { DENCIA }\end{array}$ \\
\hline MCC-13 & 13,84 & 4,2 & 30,51 & $\mathrm{AM}(\mathrm{PC})$ & MNC-021 & 19,61 & 4,7 & 54,12 & SR (PS) \\
\hline MNC-048 & 14,15 & 4,2 & 31,2 & SR (PS) & MCC-4 & 20,25 & 5,05 & 64,42 & $\mathrm{AM}(\mathrm{PN})$ \\
\hline MNC-045 & 14,44 & 4,5 & 36,55 & SR (PS) & MNC-083 & 20,66 & 5,2 & 69,83 & SR (PS) \\
\hline MAM-65 & 14,44 & 3,75 & 25,38 & PG $(\mathrm{CN})$ & MG-4 & 20,76 & 5,2 & 70,16 & GUA (SN) \\
\hline MCC-9 & 14,88 & 4,7 & 41,08 & $\mathrm{AM}(\mathrm{PC})$ & MNC-052 & 21,15 & 4,95 & 64,8 & SR (PS) \\
\hline MCC-17 & 14,93 & 4 & 29,86 & $\mathrm{AM}(\mathrm{PC})$ & MNC-063 & 21,28 & 5,1 & 69,18 & SR (PS) \\
\hline MCC-2 & 14,93 & 4,3 & 34,82 & $\mathrm{AM}(\mathrm{PC})$ & MCC-16 & 21,34 & 4,55 & 55,22 & $\mathrm{AM}(\mathrm{PN})$ \\
\hline MNC-073 & 15,56 & 4,3 & 35,96 & SR (PS) & MAM-14-73 & 21,45 & 4,3 & 49,57 & PG $(\mathrm{CN})$ \\
\hline MAM-72 & 15,64 & 4,3 & 36,14 & $\mathrm{PG}(\mathrm{CN})$ & MNC-008 & 23,13 & 5,5 & 87,46 & SR (PS) \\
\hline MCC-6 & 15,8 & 4,1 & 33,19 & $\mathrm{AM}(\mathrm{PC})$ & MAM-50 & 23,5 & 4,9 & 70,52 & PG $(\mathrm{CN})$ \\
\hline MAM-58 & 15,85 & 4,65 & 42,83 & PG (CN) & MNC-019 & 23,72 & 5,3 & 83,28 & SR (PS) \\
\hline MNC-044 & 17,12 & 4,6 & 45,28 & SR (PS) & MNC-072 & 23,9 & 5 & 74,68 & SR (PS) \\
\hline MCC-7 & 17,38 & 4,4 & 42,05 & $\mathrm{AM}(\mathrm{PC})$ & MAM-41 & 25,06 & 5,7 & 101,77 & PG (CN) \\
\hline MNC-060 & 17,4 & 3,7 & 29,77 & SR (PS) & MAM-52 & 25,16 & 4,5 & 63,68 & $\mathrm{PG}(\mathrm{CN})$ \\
\hline MNC-013 & 17,91 & 4,5 & 45,31 & SR (PS) & MCC-8 & 25,22 & 6 & 113,49 & $\mathrm{AM}(\mathrm{PC})$ \\
\hline MNC-041 & 17,95 & 4,6 & 47,5 & SR (PS) & MAM-66 & 25,4 & 5,4 & 36,7 & $\mathrm{PG}(\mathrm{CN})$ \\
\hline MCC-25 & 18,22 & 4,6 & 48,19 & $\mathrm{AM}(\mathrm{PN})$ & MCC-26 & 25,44 & 4,9 & 76,32 & VG (PC) \\
\hline MNC-075 & 18,28 & 4 & 36,56 & SR (PS) & MNC-088 & 26 & 5,3 & 91,29 & SR (PS) \\
\hline MACC-34 & 18,6 & 4,7 & 51,35 & CC (SN) & MNC-080 & 26,32 & 5,5 & 99,52 & SR (PS) \\
\hline MNC-068 & 18,79 & 4,7 & 51,85 & SR (PS) & MCC-22 & 28,57 & 4,9 & 85,71 & $\mathrm{AM}(\mathrm{PC})$ \\
\hline MNC-076 & 19,22 & 4,6 & 50,83 & SR (PS) & MACC-7 & 41,00 & 6,3 & 203,41 & CC (SN) \\
\hline MNC-025 & 19,22 & 4,8 & 55,35 & SR (PS) & MCC-24 & 48,2 & 6,6 & 262,44 & $\mathrm{AM}(\mathrm{PC})$ \\
\hline
\end{tabular}

Tablas 4. Características técnicas de los torteros reciclados (3)

\begin{tabular}{|c|c|c|c|c|c|c|c|c|c|}
\hline $\begin{array}{l}\text { REPOSI- } \\
\text { TORIO }\end{array}$ & $\begin{array}{c}\text { PESO } \\
\text { (g) }\end{array}$ & $\begin{array}{l}\text { DIÁMETRO } \\
\text { (cm) }\end{array}$ & $\begin{array}{c}\text { INERCIA } \\
\left(\mathrm{g} / \mathrm{cm}^{2}\right)\end{array}$ & $\begin{array}{l}\text { PROCE- } \\
\text { DENCIA }\end{array}$ & $\begin{array}{c}\text { REPOSI- } \\
\text { TORIO }\end{array}$ & $\begin{array}{l}\text { PESO } \\
\text { (g) }\end{array}$ & $\begin{array}{l}\text { DIÁMETRO } \\
\text { (cm) }\end{array}$ & $\begin{array}{c}\text { INERCIA } \\
\left(\mathrm{g} / \mathrm{cm}^{2}\right)\end{array}$ & $\begin{array}{l}\text { PROCE- } \\
\text { DENCIA }\end{array}$ \\
\hline MARC-3 & 3,03 & 2,2 & 1,83 & EMB (CS) & UNLP-2 & 15 & 3,05 & $S / D$ & VR (CS) \\
\hline MNC-014 & 7,43 & 2,5 & 10,49 & SR (PS) & MNC-007 & 15,58 & 4,2 & 29,85 & SR (PS) \\
\hline MNC-077 & 7,89 & 2,6 & 6,66 & $\mathrm{ACH}(\mathrm{TS})$ & MARC-1 & 15,9 & 4,1 & 28,65 & EMB (CS) \\
\hline MARC-5 & 8,99 & 4 & 17,98 & EMB (CS) & MNC-056 & 16 & 3,7 & 26,1 & SR (PS) \\
\hline MNC-004 & 10,65 & 3,5 & 14,64 & SR (PS) & UNLP-5 & 16 & 2,77 & $S / D$ & VR (CS) \\
\hline MNC-070 & 11,16 & 3,7 & 19,09 & SR (PS) & MNC-002 & 16,82 & 4,1 & 30,92 & SR (PS) \\
\hline MARC-8 & 11,38 & 3 & 12,8 & EMB (CS) & MG-0073 & 17,29 & 3,8 & 28,22 & $\mathrm{RC}(\mathrm{SCH})$ \\
\hline MARC-4 & 11,45 & 1,7 & 9,84 & EMB (CS) & UNLP-6 & 17,5 & 3,79 & S/D & S/D \\
\hline MARC-6 & 12 & 2,6 & 10,14 & EMB (CS) & MNC-003 & 17,72 & 4,1 & 32,34 & SR (PS) \\
\hline MNC-001 & 13,14 & 2,9 & 13,81 & SR (PS) & UNLP-3 & 20 & 3,25 & $S / D$ & VR (CS) \\
\hline MARC-9 & 13,27 & 3,1 & 15,92 & EMB (CS) & UNLP-4 & 20 & 4,54 & $S / D$ & VR (CS) \\
\hline MNC-058 & 13,55 & 3 & 13,51 & CB (PS) & MNC-005 & 23,67 & 5,4 & 77,62 & SR (PS) \\
\hline MARC-2 & 14,37 & 3,75 & 22,42 & EMB (CS) & UNLP-1 & 38 & 5,3 & S/D & OLA (PC) \\
\hline MARC-7 & 14,9 & 2,85 & 15,12 & EMB (CS) & MNC-006 & 45,8 & 5,7 & 89,67 & SR (PS) \\
\hline
\end{tabular}

Tabla 5.Características técnicas de los torteros modelados 
(2005:110) con lana de oveja, a partir de torteros arqueológicos con un peso entre 8 y $20 \mathrm{~g}$, produjeron hilos finos con un diámetro entre 0,2 y $0,7 \mathrm{~mm}$. Resultados similares fueron obtenidos por Martensson et al. (2006a, 2006b), quienes a partir de réplicas de torteros arqueológicos con un peso de $18 \mathrm{~g}$ produjeron hilos cuyos diámetros oscilaron entre 0,4 y 0,6 mm, como así también por Andersson y Batzner (1999:24-25), quienes concluyeron que para el mismo tipo de materia prima, artefactos con pesos entre 7 y $16 \mathrm{~g}$ no permiten producir hilos gruesos.

Estos resultados, aportan algunos indicios para sugerir posibles prestaciones en algunos artefactos incluidos en nuestra muestra. Por ejemplo, los rangos de peso utilizados en estos experimentos generalmente coinciden con aquellos relevados para la mayoría de los torteros modelados y dentro de este grupo, para la totalidad de los artefactos procedentes de CS, lo que sugiere que estos últimos no serían adecuados para producir hilos gruesos.

Respecto a las prestaciones sugeridas para torteros de menor peso, altamente representados en el grupo I por aquellos ejemplares que no superan los $10 \mathrm{~g}$, Andersson (2012) produjo hilos delgados con un diámetro promedio de $0,3 \mathrm{~mm}$, a partir de réplicas de torteros arqueológicos de $4 \mathrm{~g}$, en tanto que en los experimentos efectuados por Martensson et al. (2006a, 2006b) con artefactos de $8 \mathrm{~g}$, se obtuvieron hilos cuyos diámetros oscilaron entre 0,3 y $0,4 \mathrm{~mm}$.

La variable de mayor divergencia entre ambos grupos, a parte del espesor, surge de la medición del orificio central para soportar el huso. Si bien, las correlaciones de Pearson indican que en general el diámetro de las perforaciones no es proporcional al tamaño de los torteros, el 90,34\% de los artefactos reciclados incluye orificios mayores a 0,4 cm, mientras que el 79,77\% de los torteros modelados no supera esta medida.

De acuerdo a las consideraciones antes mencionadas, el tamaño de los orificios sugiere que los artefactos modelados admiten husos delgados y livianos, características compatibles con el procesamiento de fibras poco espesas y la producción de hilos finos. A su vez, dicha variable aplicada a los torteros reciclados, podría sugerir un rango más amplio de posibilidades.

Otra diferencia vinculada al funcionamiento de estos artefactos surge de los cálculos del momento de inercia (MI), cuyos resultados exponen un relativo predominio del momento inercial de los torteros reciclados (de escaso espesor) sobre aquellos modelados (de mayor espesor). La característica morfológica mayormente difundida entre estos últimos es la diferencia entre el borde, que tiende a ser más delgado, y el centro, que registra la mayor altura. Esto ocurre con los ejemplares de sección troncocónica, elíptica o acampanada, donde el peso viene determinado principalmente por el espesor cercano al eje. Esta particularidad permite obtener un peso adecuado, evitando en los bordes un mayor espesor que pueda contrarrestar la reducción del momento de inercia, prolongando el giro. El efecto de esta conformación implica la disminución del peso total a un nivel aceptable, mientras mantiene el diámetro necesario para promover un giro más largo y lento (e.g. Loughran-Delahunt 1996:56). Por otra parte, la mayor elevación alrededor de la perforación central posibilita aumentar la superficie en contacto con el huso, mejorando la estabilidad del conjunto. Estas características sugieren que generalmente los torteros modelados no cilindricos, presentan una mayor performance que los ejemplares reciclados.

Entre los torteros modelados, el 86,37 $\%$ de los artefactos expone MI menores a $30 \mathrm{~g} / \mathrm{cm}^{2}$, mientras que el resto del conjunto presenta un valor máximo cercano a $90 \mathrm{~g} / \mathrm{cm}^{2}$, en tanto que los torteros recicla- 
dos con MI dentro de este rango, representan el 66,67 \%, con valores máximos para el resto del conjunto superiores a $200 \mathrm{~g} /$ $\mathrm{cm}^{2}$. De acuerdo a los experimentos de Hochberg (1980:40, citado en Loughran-Delahunt 1996:18), un mayor MI permitiria mayores posibilidades de procesar fibras pesadas y de mayor tenacidad.

En este sentido, algunos torteros del primer grupo con elevados momentos inerciales, serían más adecuados para procesar fibras de mayor espesor, como así también para producir hilos gruesos o de más de una torsión, posibilidad ausente entre los ejemplares modelados procedentes de CS $\left(\mathrm{MI}=9,84-28,65 \mathrm{~g} / \mathrm{cm}^{2}\right)$. En resumen, los torteros del segundo grupo sugieren inercias moderadas, compatibles con el procesamiento de fibras livianas y giros relativamente veloces, en tanto que los artefactos reciclados, al incluir un rango de mayor amplitud en este valor (2-262,44 g/ $\mathrm{cm}^{2}$ ), permitirian mayores posibilidades de procesamiento y producción en el rango de fibras y diámetros del hilo obtenido.

Según los cálculos de desempeño en base al momento inercial, los especímenes más pequeños cuyos valores de I resultan menores a $2 \mathrm{~g} / \mathrm{cm}^{2}$, (que en nuestra muestra de torteros reciclados presentan diámetros menores a $2,5 \mathrm{~cm}$ y peso inferior a 3 g) posiblemente no fueron utilizados como contrapesos del huso, integrando otra categoria artefactual ( $v . g$. adornos, miniaturas, etc.) (Sauvage 2013: 203).

Por último, la otra variable de mayor divergencia entre ambos grupos se refiere al espesor, el cual entre los artefactos reciclados no supera los $0,7 \mathrm{~cm}$, en tanto que entre los artefactos modelados el 79,31\% de la muestra oscila entre 1 y $1,7 \mathrm{~cm}$. Si bien resulta dificil determinar en qué grado los atributos morfológicos se vinculan a aspectos funcionales o estilísticos, los torteros de escaso espesor tienden a producir una rotación relativamente lenta del eje, mientras que aquellos de mayor espesor giran más rápido, pero durante un período de tiempo más breve (McCafferty y McCafferty 2008), es decir que admiten un menor movimiento inercial.

En los estudios tecnológicos y funcionales los torteros son analizados como artefactos unitarios, donde el peso, como fue observado anteriormente resulta una variable crítica. Nos preguntamos si para los discos del grupo I, debido a su morfología de espesor delgado y superficies planas, se podría pensar que pudieron utilizarse alternativamente solos o superpuestos, lo que habría permitido aumentar el peso y ajustar el giro según las necesidades del hilado.

Entendemos que todas estas variables deben ser analizadas en conjunto y no por separado para una aproximación teórica vinculada al desempeño de los torteros.

A partir de estos datos, los resultados de los experimentos efectuados por los autores antes mencionados (Andersson 2012; Andersson y Batzner 1999; Barber 1991; Grömer 2005; Hochberg 1980, citado en Loughran-Delahunt 1996; Martensson et al. 2006a, 2006b), si bien se refieren a una materia prima inexistente en tiempos prehispánicos, permiten sugerir el tipo de prestaciones que los torteros admiten en relación a su peso y MI.

De lo dicho hasta aquí, se sugieren dos hipótesis, vinculadas a la funcionalidad de los torteros que integran la muestra en análisis: En el caso de los torteros reciclados, el amplio rango de pesos y MI calculados podría estar relacionado con la elaboración de distintos productos, sea por el diámetro del hilo obtenido o por el número de torsiones, como así también su aptitud para procesar un mayor rango de fibras. La amplitud de prestaciones que este conjunto ofrece también puede ser observada en la variación del diámetro de los orificios que soportan el huso (entre 0,3 y 0,9 cm).

En el caso de los torteros modelados, la mayor concentración en un rango más 
acotado para estas magnitudes, especialmente en el conjunto proveniente de CS, podría indicar una mayor especificidad en el procesamiento de fibras y productos obtenidos. En este caso hilos finos de determinados diámetros a partir de fibras livianas y medianas.

Cabe aclarar que la división propuesta para estas magnitudes surge de una clasificación metodológica, de modo que los limites que separan a un conjunto de otro, si bien discriminan grupos de artefactos con prestaciones similares, admiten una relativa flexibilidad.

Por otra parte, un aspecto que no debe eludirse al proponer una interpretación, resulta la incidencia del operador como una variable a tener en cuenta, ya que en trabajos etnográficos la elección de determinados torteros a veces se ve condicionada por la preferencia personal. Andersson (2012) demostró en ensayos experimentales de hilado que, aunque se utilice el mismo huso y el mismo material de fibra de lana preparado, existe una pequeña pero significativa diferencia en el diámetro medio del hilo producido (5-13 \%) por dos hilanderas diferentes. En otro orden, la misma autora comprobó también que la elección y preparación de las fibras afecta el resultado, y que el mismo huso puede utilizarse para producir tipos ligeramente diferentes de hilo.

En otro orden, un dato técnico de importancia sugiere que las limitaciones que presenta un tortero de elevado peso para producir hilos finos o procesar fibras delgadas, pueden superarse cuando el mismo es apoyado en el piso o sobre un bol, lo que produce la pérdida de gravedad y modificaciones en la inercia (Grömer 2005:110). Por este motivo, los cálculos que hemos realizado se aplican solamente a las tareas de hilado realizadas con el huso suspendido o libre.

\section{Consideraciones finales}

El estudio preliminar sobre las características tecnológicas de un conjunto de torteros arqueológicos, procedentes de las sierras de Córdoba, ha permitido obtener información inédita acerca de las prestaciones que los mismos admiten. Para una aproximación hacia sus aspectos funcionales, estos artefactos fueron analizados como materiales dinámicos, en un ejercicio teórico destinado a recrear las funciones para las que fueron diseñados.

Las diferencias morfológicas y técnicas para su elaboración exponen dos tipos principales de torteros: reciclados y modelados. Los artefactos del primer tipo presentan una amplia distribución en el área serrana, mientras que los del segundo tipo proceden de sitios puntuales con una baja frecuencia de hallazgos. Esta tendencia expone una excepción en la porción austral del Valle de Calamuchita, donde la presencia de torteros modelados resulta significativamente mayoritaria y la escasa presencia de ejemplares reciclados evidencia una particularidad que la aleja del promedio general.

El análisis preliminar de las características tecnológicas y funcionales aplicado a los artefactos de ambos grupos, permitió exponer algunas diferencias vinculadas a su desempeño y a las posibilidades productivas, lo que implicaría prestaciones diferentes para cada tipo.

Los parámetros medidos en los torteros reciclados, sugieren para estos artefactos la posibilidad de elaborar diversos productos (hilos finos, medianos, gruesos y con más de una torsión, con énfasis en los dos primeros), a partir de un amplio rango de fibras. A su vez, los parámetros que surgen de las mediciones efectuadas en los torteros modelados, en la mayoría de estos artefactos serian compatibles con la producción de hilos finos y medianos, a partir de un rango más acotado de fibras. Dentro 
de este tipo, los ejemplares procedentes de la porción austral del Valle de Calamuchita reúnen de forma exclusiva estas especificidades funcionales. Esta tendencia, al excluir mayormente la producción de ejemplares reciclados, que abarca un mayor espectro de posibilidades, reduce de modo significativo la variabilidad de los productos obtenidos, lo que podría indicar que1@s hilander@s de dicha área muestran una preferencia en la elaboración de hilos de determinadas características.

\section{Agradecimientos}

A Gabriela Luján de "Monte tus Tintes" y al Grupo Agricultoras Familiares y Artesanas del Departamento Ojo de Agua (Santiago del Estero) por la valiosa información sobre las tradiciones hilanderas. A los evaluadores que contribuyeron a mejorar el manuscrito original

\section{Notas}

1. La autora propuso para un conjunto de torteros procedentes de Teotihuacán (México), que aquellos ejemplares con un peso mayor a $20 \mathrm{~g}$ se utilizaron para el procesamiento del magüey (Agave sp.), en tanto que aquellos por debajo de este peso, fueron utilizados para el hilado del algodón (Gossypium sp.).

2. Los autores proponen un análisis que contempla las condiciones de producción y consumo de imágenes visuales, sobre objetos diversos de arte mueble y arte rupestre, en un espacio de escala regional. El patrón detectado diferencia claramente dos áreas que tienden a ser excluyentes. La primera, denominada área fronteriza, representada por espacios relativamente "abiertos", con una colonización menos arraigada, por parte de grupos con diferentes orígenes, provenientes de procesos migratorios con pautas de movilidad estacional, formas de bilocalidad e interacción a larga distancia. Dicha área presenta un marcado desarrollo del arte rupestre y según la hipótesis propuesta, este habría actuado como una forma visual comprometida en la significación del entorno, asegurando la comunicación en un marco de tensiones asociadas a la construcción de la territorialidad, en paisajes fronterizos y de perfil multicultural. La segunda, denominada de colonización arraigada, se caracteriza por una mayor densidad demográfica y profundidad temporal. En dicha área, el arte mueble constituyó un estilo emblemático plasmado en la decoración cerámica y de una variedad de objetos de uso cotidiano, que habrian aportado a las estrategias de identificación y establecimiento de límites sociales en un doble sentido. Por un lado señalando diferencias "hacia afuera", es decir hacia comunidades externas al área de producción y consumo, que manejaban otros estilos emblemáticos. Por otro lado, indicando diversos planos de diferenciación interna, es decir "hacia adentro", en el contexto de un complejo campo de relaciones sociales, dado por el mayor caudal demográfico e historia compartida. En este sentido la gran variabilidad y los patrones en los repertorios iconográficos pudieron denotar matices o variaciones, ya sean de tipo local (entre comunidades vecinas, entre un valle y otro), jerárquico o de género, entre otras posibles dimensiones.

3. González (1943) presenta 37 torteros modelados procedentes de Villa Rumipal (porción austral del Valle de Calamuchita), de los cuales 21 presentan decoración incisa.

\section{Bibliografia}

ANDERSSON STRAND, E. 2012. From spindle whorls and looms weights to fabric in the Bronze Age Aegean and Eastern Mediterranean. En Aegaeum 33 Annales liégeoises et pas Piennes d'archéologie égéenne. Kosmos: Jewellery, adornment and textiles in the Aegean Bronze Age. Proceedings of the 13 th International Aegean Conference/ 13 $e$ Rencontre égéenne internationale, editado por M. Nosch y R. Laffineur, pp. 207-214. University of Copenhagen, 
Tissera L. - "Una aproximación a los estudios tecnológicos de los torteros indígenas ..."

Danish National Research Foundation's Centre for Textile Research, Peetersleuven, Liege.

ANDERSSON STRAND, E. y A. BATZNER. 1999. Spinning wool: now and then. The common thread. Textile production during the Late Iron Age - Viking Age. University of Lund, Institute of Archaeology Report Series No. 67, Lund.

ARGUELLO DE DORSCH, E. 1983. Investigaciones arqueológicas en el Departamento Punilla. Comechingonia 1(1):4160.

ARGUELLO DE DORSCH, E. y E.E. BERBERIÁN. 1985. Investigaciones arqueológicas en el yacimiento La Playa (Dpto. Punilla - Córdoba). Comechingonia 5(3):139-151.

BARBER, E.J.W. 1991. Prehistoric Textiles: The Development of Cloth in the Neolithic and Bronze Ages. Princeton University Press, Princeton.

BERBERIÁN, E.E. 1984. Potrero de Garay: una entidad cultural tardía de la región serrana de la provincia de Córdoba (República Argentina). Comechingonia 4(2):71-138.

BERBERIÁN, E.E. 1987[1572]. Crónicas del Tucumán, Siglo XVI. Conquistadores de indias I. Editado por Comechingonia, Revista de Antropología e Historia, Córdoba.

BERBERIÁN, E.E. y M. ROLDÁN. 2003. Limitaciones a la producción agrícola, estrategias de manejos de terrenos cultivables y ampliación de la dieta en comunidades formativas de la region serrana de la provincial de Córdoba. Relaciones de la Sociedad Argentina de Antropología 28:117-131.

BIRD, J., 1979. Fibers and spinning procedures in the Andean area. En Tools for eternity: pre-Columbian workbaskets as textile production toolkits and grave offerings, editado por A. Rowe, E.P. Benson y A.L. Schaffer, pp. 13-18. The Textile Museum and Dumbarton Oaks, Was- hington DC.

BRUMFIEL, E.M., 1996. The quality of tribute cloth: the place of evidence in archaeological argument. American Antiquity 61(3):453-462.

CARPENTER, L.B.; G.M. FEINMAN y L.M. NICHOLAS. 2012. Spindle whorls from El Palmillo: economic implications. $\mathrm{La}$ tin American Antiquity 23(4):381-400.

CHASE, A.; D. CHASE; E. ZORN y W. TEETER. 2008. Textiles and the Maya archaeological record. Gender, power, and status in Classic Period Caracol, Belize. Ancient Mesoamerica 19:127142 .

CHMIELEWSKI, T.J. y L. GARDYNSKI. 2010. New frames of archaeometrical description of spindle whorls: a case study of the Late Eneolithic spindle whorls from the $1 \mathrm{C}$ site in Grodek, District of Hrubieszow, Poland. Archaeometry 52(5):869-881.

CONLEE, C.A. 2000. Late prehispanic occupation of Pajonal Alto, Nasca, Peru: Implications for imperial collapse and societal reformation. Ph.D. Dissertation, University of California at Santa Barbara, Santa Barbara.

GONZÁLEZ, A.R. 1943. Arqueología del Yacimiento indigena de Villa Rumipal (provincia de Córdoba). Publicaciones del Instituto de Arqueología, Lingüística y Folklore "Dr. Pablo Cabrera" (Universidad Nacional de Córdoba) 4:1-71.

GRÖMER, K. 2005. Efficiency and technique. Experiments with original spindle whorls. En Hallstatt textiles. Technical analysis. Scientific investigation and experimenton Iron Age textiles, British Archaeological Reports International 1351, editado por P. Bichler, K. Grömer, R. Hofmann-de Keijzer, A. Kern y H. Reschreiter, pp. 107-116. Archaeopress, Oxford.

GUINEA BUENO, M. 2004. De lo duradero a lo perecedero, II: Técnicas textiles, producción y uso del tejido prehispá- 
nico en Esmeraldas, Ecuador. Revista Española de Antropología Americana 34:63-84.

HERNÁNDEZ, H. y N. PENICHE. 2012. Los malacates arqueológicos de la península de Yucatán. Ancient Mesoamerica 23(2):441-459.

KOSSOWSKA-JANIK, D.M. 2016. Cotton and Wool: Textile Economy in the Serakhs Oasis during the Late Sasanian Period, the case of spindle whorls from Gurukly Depe (Turkmenistan). Ethnobiology Letters 7(1):107-116.

LEMA, V. y A. CAPPARELLI. 2007. El algodón (Gossypium sp.) en el registro arqueológico del Noroeste argentino: su presencia pre y post-hispánica. En $\mathrm{Pa}$ leoetnobotánica del Cono Sur: estudios de casos y propuestas metodológicas, editado por B. Marconetto, N. Oliszewsky y P. Babot, pp. 49-78. Museo de Antropología, Facultad de Filosofia y Humanidades, Universidad Nacional de Córdoba, Ferreyra Editor, Córdoba.

LÓPEZ CAMPENY, M.S. 2011-2012. Retomando el hilo... los torteros arqueológicos de Santiago del Estero. Un giro a la discusión, primeros resultados y propuesta de investigación. Cuadernos del Instituto Nacional de Antropología y Pensamiento Latinoamericano 23 (1):37-54.

LÓPEZ CAMPENY, M.S. 2016. El textil antes del textil...análisis del instrumental arqueológico como referente de prácticas de producción textil. Boletín del Museo Chileno de Arte Precolombino 21(2):119-136.

LOUGHRAN-DELAHUNT, I. 1996. A functional analysis of Northwest Coast spindle whorls. Tesis de Maestría, Western Washington University, Washington.

LUNDIN, L.W. 2016. Elevated crafts textile production at fortified hilltop settlements from the migration period. Master's Thesis in Archaeology, Department of Archaeology and Ancient History Lund
University

MARCELLINO, A.; E.E. BERBERIÁN y J. PÉREZ. 1967. El yacimiento arqueológico de Los Molinos (Dpto. Calamuchita, Córdoba). Publicaciones del Instituto de Antropología (a)

26:2-68.

MARTENSSON, L.; E. ANDERSSON; M.L. NOSCH y A. BATZER. 2006a. Technical Report Experimental Archaeology Part 1: 2005-2006. Tools and Textiles. Texts and Contexts Research Programme. The Danish National Research Foundation's Centre for Textile Research (CTR):1-12.

MARTENSSON, L.; E. ANDERSSON; M.L. NOSCH y A. BATZER. 2006b. Technical Report Experimental Archaeology Part 3: 2 whorl or bead? 2006. Tools and Textiles. Texts and Contexts Research Programme. The Danish National Research Foundation's Centre for Textile Research (CTR):1-12.McCAFFERTY S.D. y G.G. McCAFFERTY. 2000. Textile Production in Postclassic Cholula, Mexico. Ancient Mesoamerica 11:39-54.

McCAFFERTY S.D. y G.G. McCAFFERTY. 2008. Spinning and weaving tools from Santa Isabel, Nicaragua. Ancient $\mathrm{Me}$ soamerica 19:143-156.

MEDINA, M.; S. PASTOR y D.E. RIVERO. 2014. Osteometría y diferenciación de especies de camélidos en sitios arqueológicos de las Sierras Centrales (Argentina). Tendencias, problemas y perspectivas. Intersecciones en Antropología 15(2):339-351.

MILLAIRE J. 2008. Moche textile production on the Peruvian north coast. En The art and archaeology of the Moche, editado por S. Bourget y K. Jones, pp. 229-245. University of Texas Press, Austin.

MULVANY, E.; S. SORIA y C. MANJARRES. 1992. Aspectos de la organización económica en comunidades tardías. Producción de hilos y torteros. Cuadernos del INAPL 4:155-165. 
NIELSEN, A. y F. ROLDÁN. 1991. Asentamientos satélites y asentamientos agrícolas permanentes: el caso "El Fantasio" (Dpto. Punilla, Córdoba). Comechingonia 7(8):65-75.

PARSONS, M.H. 1972. Spindle whorls from the Teotihuacán Valley, Mexico. En Miscellaneous Studies in Mexican Prehistory. Anthropological Papers, editado por M. Spence, J. Parsons y M. Parsons, pp. 45-79. Museum of Anthropology, University of Michigan, .

PASTOR, S.; M. MEDINA y E.E. BERBERIÁN. 2013. Poblados, casas y maizales, Arqueología del espacio residencial y productivo en las Sierras Centrales de Argentina (ca. 1100-300 AP). Revista Española de Antropología Americana 43(1):31-55.

PASTOR, S. y L.E. TISSERA. 2016 Comunicación, identidad y límites sociales prehispánicos (sur de las Sierras Pampeanas, Argentina). Análisis de imágenes visuales en arte mueble y rupestre. En Actas del XIX Congreso Nacional de Arqueología de Argentina, pp. 23662372. San Miguel de Tucumán. Facultad de Ciencias Naturales e I.M.L.

RAHMSTORF, L. 2015. An introduction to the investigation of archaeological textile tool. En Tools, textile and contexts. Investigating textile production in the Aegean and Eastern Mediterranean Bronze Age. Serie Ancient textiles Vol. 21, editado por E. Andersson Strand y M. Nosch, pp. 1-23. Oxbow, Oxford.

SAUVAGE, C. 2013. Spinning from old threads: the whorls from Ugarit at the Musée d'Archéologie Nationale (SaintGermain-en-Laye) and at the Louvre. En Textile production and consumption in the Ancient Near East. Ancient textiles, editado por M. Nosch, H. Koefoed y E. Andersson Strand, pp. 189-214. Oxford.

SERRANO, A. 1945. Los comechingones. Serie Aborígenes argentinos. Vol. I,
Instituto de Arqueologia, Lingüística y Folklore de la Universidad Nacional de Córdoba. Córdoba.

SMITH, M.E. y K.G. HIRTH. 1988. The development of prehispanic cotton-spinning technology in Western Morelos, Mexico. Journal of Field Archaeology 15:349-358.

SORIA, S. 1999. Estudios descriptivos: estrategias en el análisis de torteros. En Actas del XII Congreso Nacional de Arqueología Argentina. Tomo I: 382-395. La Plata.

SPLITSTOSER, J. 2009. Weaving the structure of the cosmos: cloth, agency, and worldview at Cerrillos, an early Paracas site in the Ica valley, Peru. Tesis doctoral, The Catholic University of America, Washington D.C.

WILLIAMS, V.I. 1983. Evidencia de actividad textil en el establecimiento incaico Potrero Chaquiago (provincia de Catamarca). Relaciones de la Sociedad Argentina de Antropología 15:49-59. 
